\title{
Preface to the special issue dedicated to Andries E. Brouwer
}

\author{
Aart Blokhuis ${ }^{1}$ • Edwin R. van Dam² . \\ Willem H. Haemers ${ }^{2}$. Jack H. Koolen ${ }^{3}$
}

Published online: 23 November 2016

(C) Springer Science+Business Media New York 2016

On April 3, 2016, Andries Evert Brouwer became 65 years old. To celebrate this occasion we have invited mathematical friends of Andries to contribute to a journal volume in his honour. The result is the present special issue of Designs, Codes and Cryptography.

Andries' major achievements concern discrete mathematics. He has important contributions in coding theory, design theory and algebraic graph theory. His contributions vary from ingenious theoretical theorems, to computer generated tables. The tables with feasible parameters for strongly regular graphs and with bounds for error correcting codes are the standard source of information for many researchers. World famous is his standard work (with Arjeh Cohen and Arnold Neumaier) on distance-regular graphs which appeared in 1989 and is still the most important work on the subject. More recently, he wrote the book 'Spectra of Graphs' (with Willem Haemers), which became an important reference in algebraic graph theory. Andries wrote about 200 research papers, and has 140 coauthors. Among them are Aart Blokhuis (on various subjects, many concerning finite geometry), Arjeh Cohen (mainly on algebraic groups, and distance-regular graphs), Willem Haemers (graph spectra), Jack Koolen (distance-regular graphs), Lex Schrijver (mainly on codes and designs), and Henny Wilbrink (on graphs, designs and finite geometries, in particular near polygons). Andries was supervisor of eight PhD students, namely, Kang Qingde, Ernst Lambeck, Jack Koolen, Marijn Van Eupen, Remko Riebeek, Rieuwert Blok, Tim Mussche and Çiçek Güven.

But Andries' knowledge and interest is much wider than mathematics. He was one of the developers of the Linux operating system, one of the designers of the computer game Hack, and has a very big interest in, and knowledge of, languages of the world. We refer

$凶 \quad$ Edwin R. van Dam

Edwin.vanDam@uvt.nl

Jack H. Koolen

koolen@ustc.edu.cn

1 Department of Mathematics, Eindhoven University of Technology, Eindhoven, The Netherlands

2 Department of Econometrics and Operations Research, Tilburg University, Tilburg, The Netherlands

3 School of Mathematical Sciences, University of Science and Technology of China, Hefei, China 
to the homepage http://www.win.tue.nl/ aeb/ of Andries for papers, tables and much more information concerning his works and interests.

In 1968 Andries started to study mathematics at the Free University of Amsterdam, and in 1976 he obtained his $\mathrm{PhD}$ at the same University. The title of his thesis was 'Treelike Spaces and Related Connected Topological Spaces'. His supervisors were M.A. Maurice and P.C. Baayen. Andries was employed at the CWI (Center for Mathematics and Computer Science) from 1971 to 1986. In 1986 he became professor at Eindhoven University of Technology. He retired in 2012.

Amsterdam has been Andries' hometown since his birth. He commuted by train between Amsterdam and Eindhoven until his retirement. Andries has spent much time in Denmark. There he met his wife Agnete, and became father of his two children Maja and Peter. In 2004 he obtained an honorary doctoral degree at Aalborg University.

Andries enjoys working on all sorts of problems that come his way. He is a very fast thinker, and works hard and with precision. He enjoys discussing problems with fellow mathematicians, and often comes up with a solution. During the time he was supposed to be working on his $\mathrm{PhD}$ thesis he attacked all sorts of problems without worrying about his $\mathrm{PhD}$. About this Andries said: 'In 1975 the head of the department, Cor Baayen, inquired about the progress of my thesis. I didn't know that I was supposed to work on that, but wrote something and got my PhD in 1976'. We, the guest editors of this special issue, have benefitted a lot from discussions with Andries. For each of us our research was greatly influenced by Andries Brouwer.

The present volume has 23 contributions and 51 contributors. The enthusiasm for contributing was enormous. It resulted in a very strong collection of papers, and we are very satisfied with this birthday present. We hope that Andries will be as pleased as we are at the resulting volume. 